\title{
BALANCED REGIONAL ANALGESIA - AN HYPOTHESIS
}

\section{P.J. TOMLIN AND JON GJESSING}

THERE ARE FEW AREAS in anaesthetic practise which give as much personal satisfaction to the anesthetist as a well conducted regional block. It seemed worth while to analyze why this is so. The technical process of applying the right quantity and concentration of local analgesic solution to the right place requires some skill and judgement but this is easily acquired with practice and in any case is not more than that required to conduct a good general anaesthetic for a moderately complicated surgical procedure. It is obvious that patients are in better physiological state in the immediate post-operative period than their confrères who have had general anaesthesia, but this effect is short lasting and six hours later there is little to choose between them. It appeared that the personal contact with the conscious patient, helping to tide them over a period when they are most vulnerable and potentially very frightened through an anxious period, was the principle source of this satisfaction. Further, since there was some uncertainty about the outcome in terms of patient management, when the procedure was completed it was not only the patient who was relieved.

In Sundsvall Hospital (a 1,200-bed district general hospital in Sweden) approximately 3,000 to 4,000 regional blocks are done each year. During studies with different local analgesics or tranquillizer regimes it was observed that, although the regional block was anatomically perfect with an easily definable level of analgesia and the surgeon was causing no pain, yet the patient was distressed. Tachycardia, hypotension, lacrimation sweating or even sobbing could occur. There was little hestitation in criticizing the patient management.

A double-blind trial undertaken to determine if the problems were of purely psychological origin, using an inert placebo,' showed clearly that the patients needed additional help. Other studies in which the predominant problem was anxiety, such as dental phobia, showed that it was possi-

P.J. Tomlin, M.B., B.S., F.F.A.R.C.S., Department of Anaesthetics, Queen Elizabeth Hospital, Edgbaston, Birmingham, B15 2TH, England; Jon Gjessing, M.D., Department of Anaesthetics, Sundsvall Hospital, Sundsvall, Sweden. ble to allay anxiety as intense as phobia by using benzodiazepines such as chlorazepam $50-100 \mathrm{mg}$ or diazepam $2.5-5.0 \mathrm{mg}$. Yet when these agents were given to the distressed but not particularly phobic patient they were not always successful. Since giving more benzodiazepines merely made the patient incoherent, distressed patients were given an intravenous narcotic (meperidine 25-35 $\mathrm{mg}$ ) and if this failed they were given either thiopentone or nitrous oxide.

To quantify the extent of this variation in patient management and in an attempt to identify if there were any factors in the patients circumstances which might contribute to their distress, a retrospective search of one year's anae sthetic records (up to a limit of 100 each) for six particular types of operation and regional blocks was made (Table I). The drug used to provide the regional glock was mepivacaine one per cent except for the subarachnoid blocks, in which tetracaine was used.

\section{RESULTS}

(a) Site and nature of the operation (Table I)

Of the 486 patients only 78 ( 16 per cent) could accept the operation without any adjuvant. But if the operation was on the forearm 31 per cent of patients could accept the operation without additional help. This difference is statistically significant $\left(X^{2}=20.889 ; P<0.0005\right)$. Similarly, patients undergoing operations on the knee tolerated the procedure significantly better than if the operation involved the trunk, hip or groin $\left(\mathrm{X}^{2}=\right.$ 14.786; $P<0.025$ ). Thus operations on the peripheral parts of the body produced less distress than those elsewhere.

\section{(b) Position of the patient}

The proportion of patients who did not need adjuvant help varied between four and nine per cent if they were in an abnormal position, but was 22 per cent if they were in a normal position. If they were given only a tranquillizer, then the proportion of patients remaining distressed was significantly higher if they were in an abnormal position ( 65 per cent) than if they were in a normal position (43 per cent). This difference is also statistically significant $\left(X^{2}=11.478 ; P<0.025\right)$. 
TABLE I

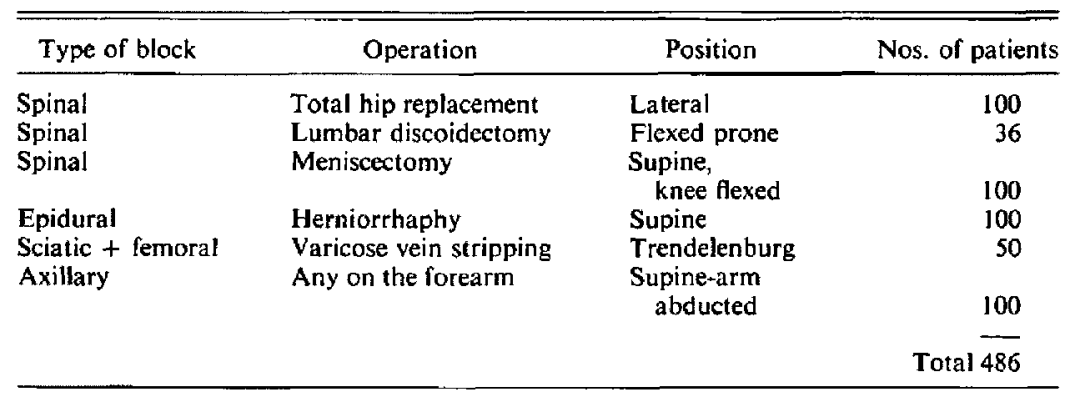

\section{(c) Delay and waiting}

In all cases there was some delay between completion of the block and the surgical incision. Factors in this delay were: waiting for the block to take effect, subsequent positioning of the patient, preparing and towelling up the surgical field and, on occasion, awaiting the arrival of the unexpectedly delayed surgeon. An unexpectedly high number of patients needed something more than a tranquillizer to settle them before the operation had even started. Considering only those who needed a narcotic, this averaged approximately 50 per cent of the patients but there was no difference between those in an abnormal and those in a normal position.

\section{(d) Failure to achieve patient comfort}

Distribution of patients requiring additional sedation is shown in Table II.

There was a persistent four per cent of patients who could not cope with a regional block, irrespective of the type of block, sedation technique or position and who required a general anaesthetic.

\section{Discussion}

From the result it is clear that many patients need help to enable them to accept operations under local analgesia. This need cannot be met with a placebo.' Benzodiazepines are capable of relieving anxiety as intense as phobia ${ }^{1,2}$ and yet many patients developed distress or remained distressed when a tranquillizer had been given. The source of this distress was not related to surgical pain since in half the cases the operation had not even started. Observation of the patients showed that the distress was of gradual onset but, if left untreated, it could become so severe as to amount to pain. The patients had great difficulty in describing this discomfort in any specific or localizing terms, but just that they did not feel well and they had a very strong desire to change their position. All were lying on a firm but well upholstered mattress of thick foam rubber. It would seem that there is another modality in patients' response which is unrelated to either surgical pain or anxiety and which needs to be catered for when dealing with patients undergoing a regional block. This would appear to be related in part to having to lie in an abnormal position, and in part to being required to remain still for a protracted period with a substantial part of the body rendered numb. It is eased in most instances by narcotics, but in a small minority even narcotics will fail and the patient must be given a general anaesthetic.

Since people can normally lie still for protracted periods (half an hour or more) without becoming distressed, for instance while awaiting operation under general anaesthesia, it would seem that having the local analgesic block and then lying still disturbs the patient's interior milieu and that this is the cause of the distress. If the patient can move periodically, as in the postoperative period, the distress appears to be eased. This would suggest that disturbance of some of the sensory input is the source of the distress, and the most likely is loss of proproception, in view of the desire to move and the effect of posture.

Thus a hypothesis could be advanced that there is a triad of surgical pain, anxiety and disturbance of proprioception which need to be catered for when conducting regional analgesia. These can be combatted by local anaesthetics, tranquillizers and a narcotic. This could be called "balanced regional analgesia".

Textbooks on regional analgesia concentrate almost exclusively on the techniques of applying the local anaesthetic drugs. Other aspects of patient care, if mentioned, are discussed under the heading of premedication. Sometimes this is very heavy medication with barbiturates the night before and on the day of operation, followed by meperidine plus hyoscine. ${ }^{4}$

The concept of balanced anaesthesia was first 


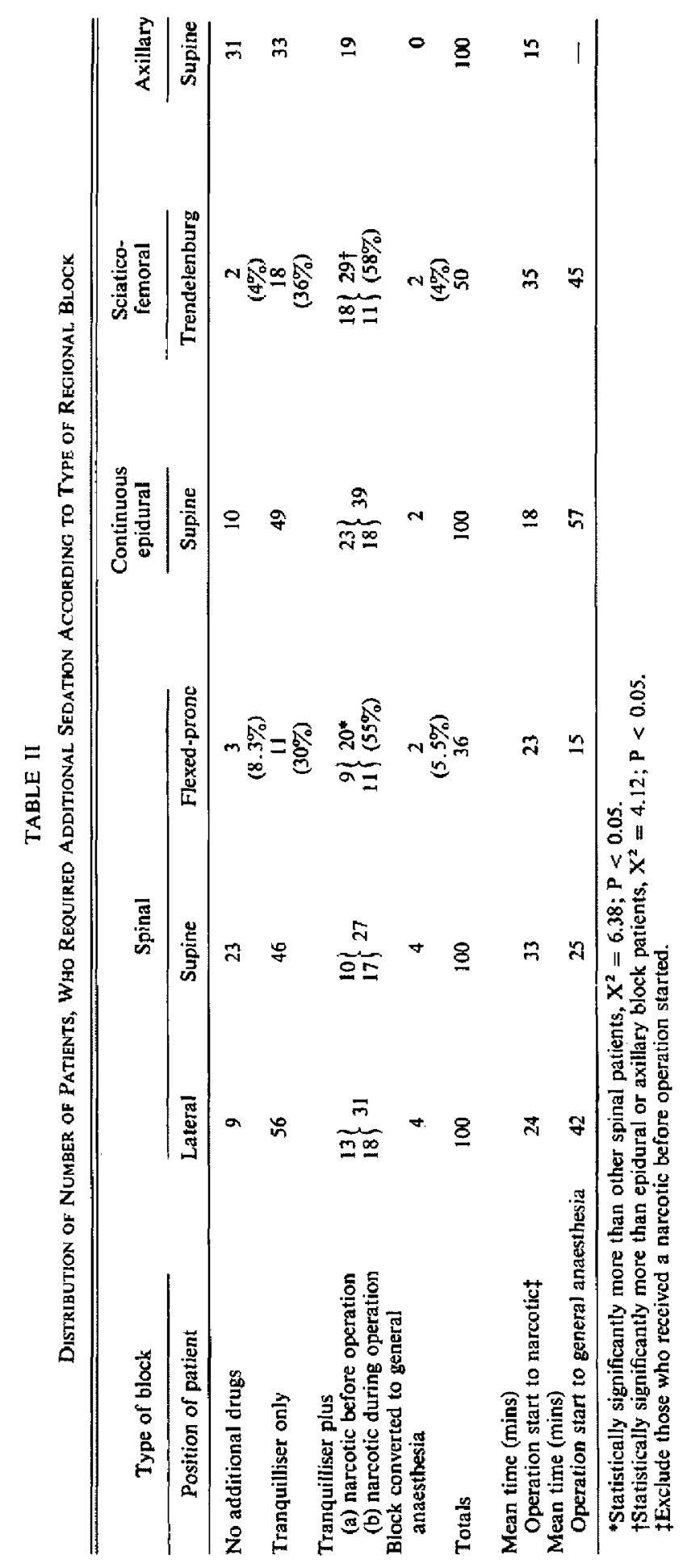


advanced by Lundy in $1926 .^{5}$ Following the in troduction of relaxants it was applied to modern general anaesthesia by Rees and Gray in $1950^{\circ}$ and modified further by Gray in $1960 .^{7}$ Balanced anaesthesia was envisaged as combatting a triad of responses requiring a triad of objectives, namely narcosis, analgesia (or reflex suppression) and relaxation. The general purpose was to use a combination of drugs, each with a selective action affecting one limb of the triad.

The hypothesis of balanced regional analgesia follows this pattern, although the limbs of the triad are different and hence the drugs are different. Nevertheless the hypothesis envisages using separate drugs to modify specific limbs of the triad.

In his anoci-association hypothesis Crile ${ }^{8}$ proposed that anaesthesia should protect the patient from all noxious stimuli, both psychic and traumatic. Although his rationale for this would not withstand critical evaluation in the light of modern knowledge, yet the principle he proposed is still valid. If there is imbalance of the cortical sensory input due to proprioceptive disturbances, such as the physical drag of an anaesthetized portion of the body, this would be an noxious stimulus from which the patient should be protected.

The advantages to the patient of regional blocks are real and are discussed by Lee. ${ }^{9}$ It could be argued that the personal satisfaction to the anaesthetist from conducting a successful block lies in his intuitive grasp of the patient's needs, the reasons for which perhaps he has not formally analyzed. The concept of a balanced regional block offers a working hypothesis for a more rational approach to this complex problem of patient care.

\section{SUMMARY}

An hypothesis is advanced, based upon observation of patients undergoing selected types of regional analgesic blocks, that total patient care during any regional analgesic technique consists of maintaining a balance of local analgesia, tranquillity and the use of a centrally acting analgesic. The latter is required to relieve non-specific distress unrelated to the operation which appears to be caused by a disturbance of sensory input to the cerebral cortex, possibly the proprioceptive input. A small group of patients will not respond to any sedation accompanying regional analgesia and need general anaesthesia. It is suggested that failure to appreciate all three parts of this triad may contribute to uncertainty of patient control during regional block.

\section{RÉSUMÉ}

Une étude des dossiers anesthésiques de malades opérés sous anesthésie régionale et groupés (six groupes) selon le type de chirurgie et de technique d'anesthésie régionale, a fait ressortir le fait que peu de malades peuvent subir une intervention sous anesthésie régionale sans l'aide de médication adjuvante. Le besoin de médication adjuvante est fonction de la nature et du site de l'intervention pratiquée, du type de blocage utilisé et de la position du malade en cours de chirurgie.

Certains malades manifestent au niveau d'inconfort très élevé non soulagé par les tranquilisants et survenant avant même le début de la chirurgie et sans rapport à la position du malade sur la table d'opération. Pour 4 pour cent de ces malades, seule l'anesthésie générale a pu corriger la situation, quelque soit la sorte d'anesthésie régionale utilisée. Cet état ne semble également pas lié au niveau d'anxiété, car les benzodiazépines utilisées sans succès chez eux sont capables de soulager des anxiétés aussi extrêmes que les phobies. Le malade devient graduellement très inconfortable et il éprouve un très grand besoin de changer de position; ceci suggère un déséquilibre des fonctions proprioceptives. Les analgésiques peuvent soulager ces symptômes.

En conclusion, la bonne conduite d'une anesthésie régionale demande l'élimination de la douleur chirurgicale, le soulagement de l'anxiété et le traitement, si besoin, des manifestations d'un déséquilibre de l'intégration proprioceptive.

\section{REFERENCES}

1. GJessing, J. \& Tomlin, P.J. Intravenous sedation and regional analgesia. Anaesthesia 32:63 (1977).

2. LaUtch, H. Dental phobia. British J. of Psychiatry I19: 151 (1971).

3. GJessing, J. \& Tomlin, P.J. Chlorazepam di potassium as an intravenous sedative during regional analgesic block. Awaiting publication (1978).

4. LUND, P.C. Principles and practice of spinal anaesthesia. p. 22, Springtield, U.S.A.: C.C. Thomas (1971).

5. LUNDY, J. Balanced Anesthesia. Minn. Med. 9: 399 (1926).

6. REES, G.J. \& GRAY, T.C. Methyl-N-Propyl ether. British Journal of Anaesthe sia 22: 83 (1950).

7. Gray, T.C. A reassessment of the signs and levels of anaesthesia. Irish J. Med. Sci. $419: 449$ (1960).

8. CrILE, G.W. The Kinetic theory of shock and its prevention through anoci association. Lancet 2: 7 (1913).

9. LeE, J.A. \& ATKINSON, R.S. Synopsis of anaesthesia. p. 412, Bristol: $J$. Wright (1968). 